\title{
Topographic Effects on the Spatial Species Associations in Diverse Heterogeneous Tropical Evergreen Forests
}

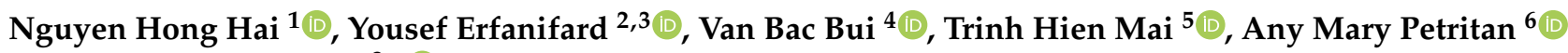 \\ and Ion Catalin Petritan ${ }^{3, *}$ \\ 1 Faculty of Silviculture, Vietnam National University of Forestry, Hanoi 08424, Vietnam; hainh@vnuf.edu.vn \\ 2 Department of Remote Sensing and GIS, College of Geography, University of Tehran, \\ Tehran 1417466191, Iran; erfanifard@ut.ac.ir \\ 3 Faculty of Silviculture and Forest Engineering, Transilvania University, ROU-500123 Brasov, Romania \\ 4 Faculty of Forest Resources \& Environmental Management, Vietnam National University of Forestry, \\ Hanoi 08424, Vietnam; buibac80@gmail.com \\ 5 College of Wood Industry and Interior Design, Vietnam National University of Forestry, \\ Hanoi 08424, Vietnam; maith@vnuf.edu.vn \\ 6 National Institute for Research-Development in Forestry 'Marin Dracea', 077190 Voluntari, Romania; \\ apetritan@gmail.com \\ * Correspondence: petritan@unitbv.ro
}

Citation: Hai, N.H.; Erfanifard, Y.; Bui, V.B.; Mai, T.H.; Petritan, A.M.; Petritan, I.C. Topographic Effects on the Spatial Species Associations in Diverse Heterogeneous Tropical Evergreen Forests. Sustainability 2021, 13, 2468. https://doi.org/10.3390/ su13052468

Academic Editor: Petros Ganatsas

Received: 2 February 2021

Accepted: 21 February 2021

Published: 25 February 2021

Publisher's Note: MDPI stays neutral with regard to jurisdictional claims in published maps and institutional affiliations.

Copyright: (c) 2021 by the authors. Licensee MDPI, Basel, Switzerland. This article is an open access article distributed under the terms and conditions of the Creative Commons Attribution (CC BY) license (https:/ / creativecommons.org/licenses/by/ $4.0 /)$.

\begin{abstract}
Studying spatial patterns and habitat association of plant communities may provide understanding of the ecological mechanisms and processes that maintain species coexistence. To conduct assessments of correlation between community compositions and habitat association, we used data from two topographically different plots with 2 ha area in tropical evergreen forests with the variables recorded via grid systems of $10 \times 10 \mathrm{~m}$ subplots in Northern-Central Vietnam. First, we tested the relationship between community composition and species diversity indices considering the topographical variables. We then assessed the interspecific interactions of 20 dominant plant species using the nearest-neighbor distribution function, $D_{\mathrm{ij}}(r)$, and Ripley's $K$-function, $K_{\mathrm{ij}}(r)$. Based on the significant spatial association of species pairs, indices of interspecific interaction were calculated by the quantitative amounts of the summary statistics. The results showed that (i) community compositions were significantly influenced by the topographic variables and (ii) almost $50 \%$ significant pairs of species interactions were increased with increasing spatial scales up to $10-15 \mathrm{~m}$, then declined and disappeared at scales of 30-40 m. Segregation and partial overlap were the dominant association types and disappeared at larger spatial scales. Spatial segregation, mixing, and partial overlap revealed the important species interactions in maintaining species coexistence under habitat heterogeneity in diverse forest communities.
\end{abstract}

Keywords: coexistence; habitat heterogeneity; spatial pattern analysis; plant species association; tropical evergreen forest

\section{Introduction}

One of the main goals of community ecology is to explain the mechanisms of plant species associations which regulate their spatial distributions and the significant variations in complex communities of natural forests [1-3]. Previous studies have shown that the main drivers regulating the spatial patterns of plant communities are biotic (e.g., plant-plant interactions) and abiotic factors, such as effect of environmental conditions [4-7]. Effects of biotic and abiotic factors can occur simultaneously; however, the relative importance of the drivers may often vary at different spatial scales $[8,9]$. The effects of abiotic factors seem to be more important at large spatial scales, while the effects of biotic factors may be more important at small scales $[10,11]$. Previous investigation on plant communities $[7,12,13]$ have found that inter- and intra-specific interactions of neighboring plant individuals may 
happen at smaller spatial scales (i.e., smaller than $30 \mathrm{~m}$ ) and disappear at larger spatial scales. However, the relative importance of the drivers to the species association and the degrees to which variations operate in species interactions strongly depend on forest types and habitat conditions.

Habitat heterogeneity caused by environmental variation, such as topography, light availability, soil nutrients, and humidity, is considered as the important factor determining species coexistence $[7,14]$. Topographical variables are differentiated along environmental gradients and reflected by species association due to habitat preferences of the species $[6,15]$. For instance, Aiba et al. [16] showed that 20 of 42 species exhibited habitat association in Borneo (a tropical montane forest). In addition, Punchi-Manage et al. [17] reported that only $25 \%$ of species showed topographic association in a mixed dipterocarp forest in Sri Lanka, while 52 of 60 species were positively associated with topographic factors in subtropical forests in China [18].

The summary statistics recently applied for spatial point pattern analysis enable us to quantify pair-wise spatial interactions between plant individuals (e.g., density of individuals of one species around an individual of a focal species) by their comparison to appropriate null models $[4,19,20]$. Plants mostly interact with their neighboring individuals [21], therefore their spatial distributions may conserve imprints of inter- and intraspecific interactions that can be explored by spatial point pattern analysis [4]. For instance, aggregation of conspecifics may lead to segregation of hetero-specifics and reduce competitive exclusion since the influence of interspecific competition is disappeared $[4,22,23]$. In contrast, independent placement of individuals may be explained by a rule that conspecific individuals are placed regardless of spatial arrangement of heterospecific individuals [24], particularly in species-rich communities. Supporting this hypothesis, Wiegand et al. [4] found that the rule of independence may be a possible limitation of plant distribution in species-rich communities and explored by the stochastic geometry of biodiversity. However, environmental heterogeneity that often appears at large spatial scales may lead to complexity of analyses of species associations [14,25]. Moreover, the influence of species habitat preferences (i.e., first-order effects) may mask the effects of direct plant-plant competitive or facilitative interactions (i.e., second-order effects) $[2,7,14]$.

In the present study, we determined habitat association and species interactions of 20 dominant tree species within two topographically different plots of tropical evergreen forests that are geographically close. We asked: (i) How do the species compositions correlate with the topographic variables (i.e., elevation, slope, and aspect)? (ii) Do segregation and partial overlap of hetero-specifics dominate within the forests under habitat heterogeneity? We are further interested in (iii) at which spatial scales the species interactions can be observed? In line with previous research on diverse tropical forests, our achievements on the effects of topographic heterogeneity on ecological interactions of conspecifics and hetero-specifics may contribute to a better understanding of biodiversity dynamics in unique tropical forests.

\section{Materials and Methods}

\subsection{Study Site and Data Collection}

The study plots were located in tropical evergreen broadleaf forests in North Central Vietnam (Figure 1). The climate regime of the study region is characterized as tropical monsoon, since the average annual temperature and the average annual precipitation are $23.5{ }^{\circ} \mathrm{C}$ and $3000 \mathrm{~mm}$, respectively. In general, almost $60 \%$ to $70 \%$ of the annual precipitation falls in autumn (from October to November), while the dry season happens in spring and summer (from March to August). 


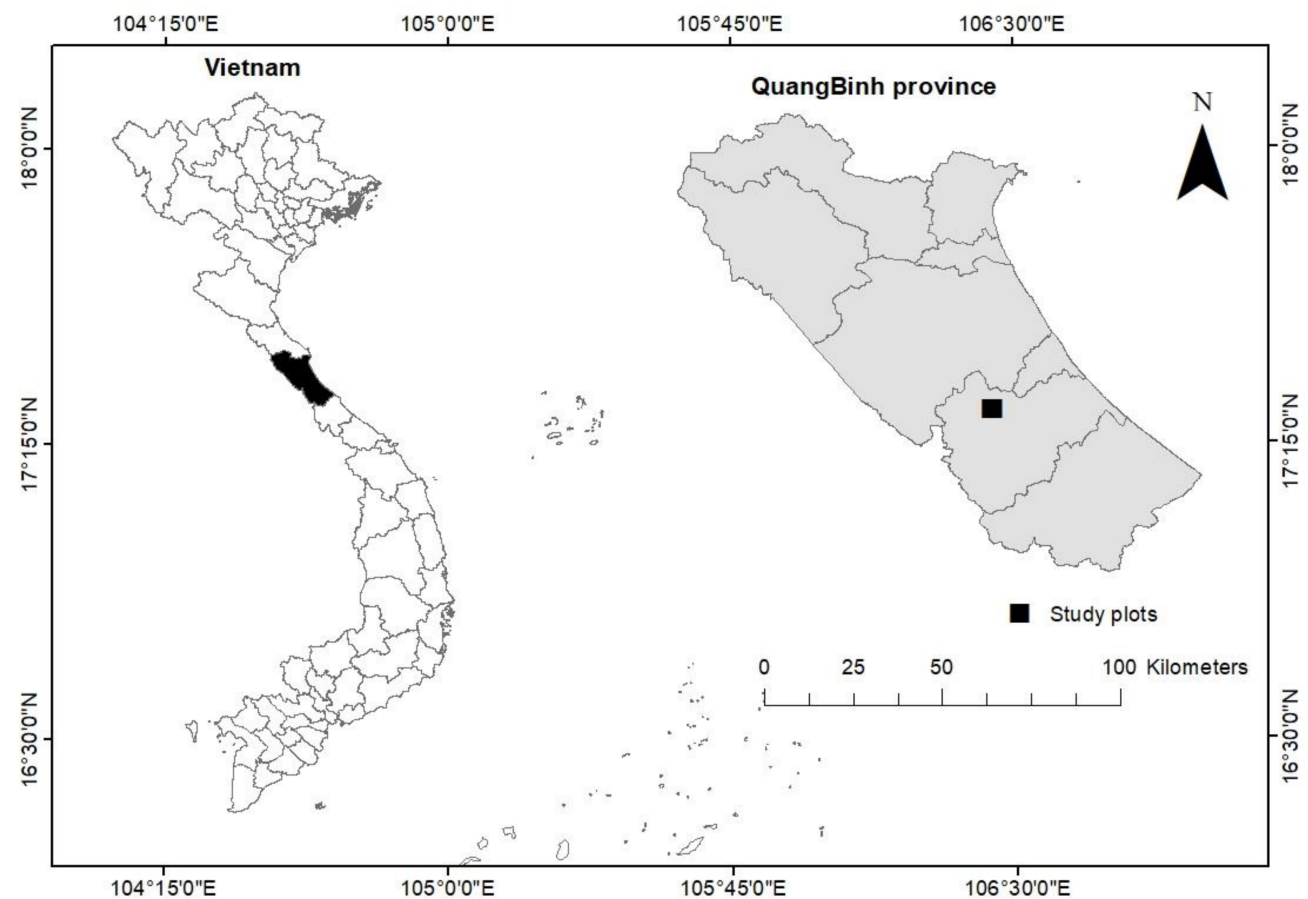

Figure 1. Maps of Vietnam, study region and plots.

The study plots of $100 \times 200 \mathrm{~m}$ (Figure 2), P1 $\left(17^{\circ} 20^{\prime} 11^{\prime \prime} \mathrm{N}, 106^{\circ} 26^{\prime} 30^{\prime \prime} \mathrm{E}\right)$ and P2 $\left(17^{\circ} 20^{\prime} 15^{\prime \prime} \mathrm{N}, 106^{\circ} 26^{\prime} 24^{\prime \prime}\right.$ E) recorded by Garmin 60 s GPS (Global Positioning System) using WGS-84 datum at the center of the plots, were designed and subdivided into two grid systems of $200(10 \times 10 \mathrm{~m})$ subplots for measuring tree individuals and topographic data. Slope of the plots ranges from 5 to 45 degrees with an elevation ranging from 119 to $184 \mathrm{~m}$ above sea level [26]. Tree individuals with dbh (diameter at breast height) $\geq 2.5 \mathrm{~cm}$ were stem-mapped within the plots and their biophysical characteristics (i.e., species type and dbh) were recorded. Canopy cover was recorded at the center of every subplot by taking hemispherical photographs of subplot canopy and assessed by the Gap light analysis mobile application [27]. The topographic variables (i.e., slope and aspect) and relative tree positions $(\mathrm{x}, \mathrm{y})$ were recorded in each subplot using a laser distance meter (Leica Disto D2) and compass. Elevation was firstly recorded by Garmin $60 \mathrm{~s}$ GPS at the lower left corner of the plot and then calculated by inclinometer for other corners within each subplot and registered as the mean of the elevation. This forest area was certified for sustainable forest management in 2011, so it has been well-protected for decades.

\subsection{Data Analysis}

\subsubsection{Community Properties}

Commonly used taxonomic diversity indices including species richness, Shannon, Pielou evenness, and Simpson indices of entropy were calculated within each subplot [28] as follows:

Species richness (S) is number of observed species.

Shannon index $(\mathrm{H})=-\sum p_{\mathrm{i}} \ln p_{\mathrm{i}}$, where $p_{\mathrm{i}}=\mathrm{n}_{\mathrm{i}} / \mathrm{N}, \mathrm{i}=1$ to $\mathrm{S}, \mathrm{n}_{\mathrm{i}}$ is number of individuals of species I, $\mathrm{N}$ is total number of individuals.

Pielou index $(\mathrm{J})=\mathrm{H} / \log \mathrm{S}$.

Simpson index $(1-\mathrm{D})=1-\sum p_{\mathrm{i}}{ }^{2}$.

Species richness is defined as the actual number of species present in each subplot; however, the Simpson index is related to the abundance of species. The Shannon index, describing the disorder and uncertainty of individual species, is particularly sensitive to the number of rare species within the study area, while the Simpson index [29] reflects the number of abundant species [30]. The diversity indices were calculated for each subplot by 
PAST ver. 3.25 software (Paleontological Statistics, https: / folk.uio.no/ ohammer/past/, accessed on 1 December 2020). Additionally, the AGB (above-ground biomass) of all species individuals was assessed by the allometric equation obtained by Chave et al. [31] for evergreen broadleaf forests: $A G B=0.12843 \times D^{2.409076}$, where $\mathrm{D}$ is $\mathrm{dbh}(\mathrm{cm})$.
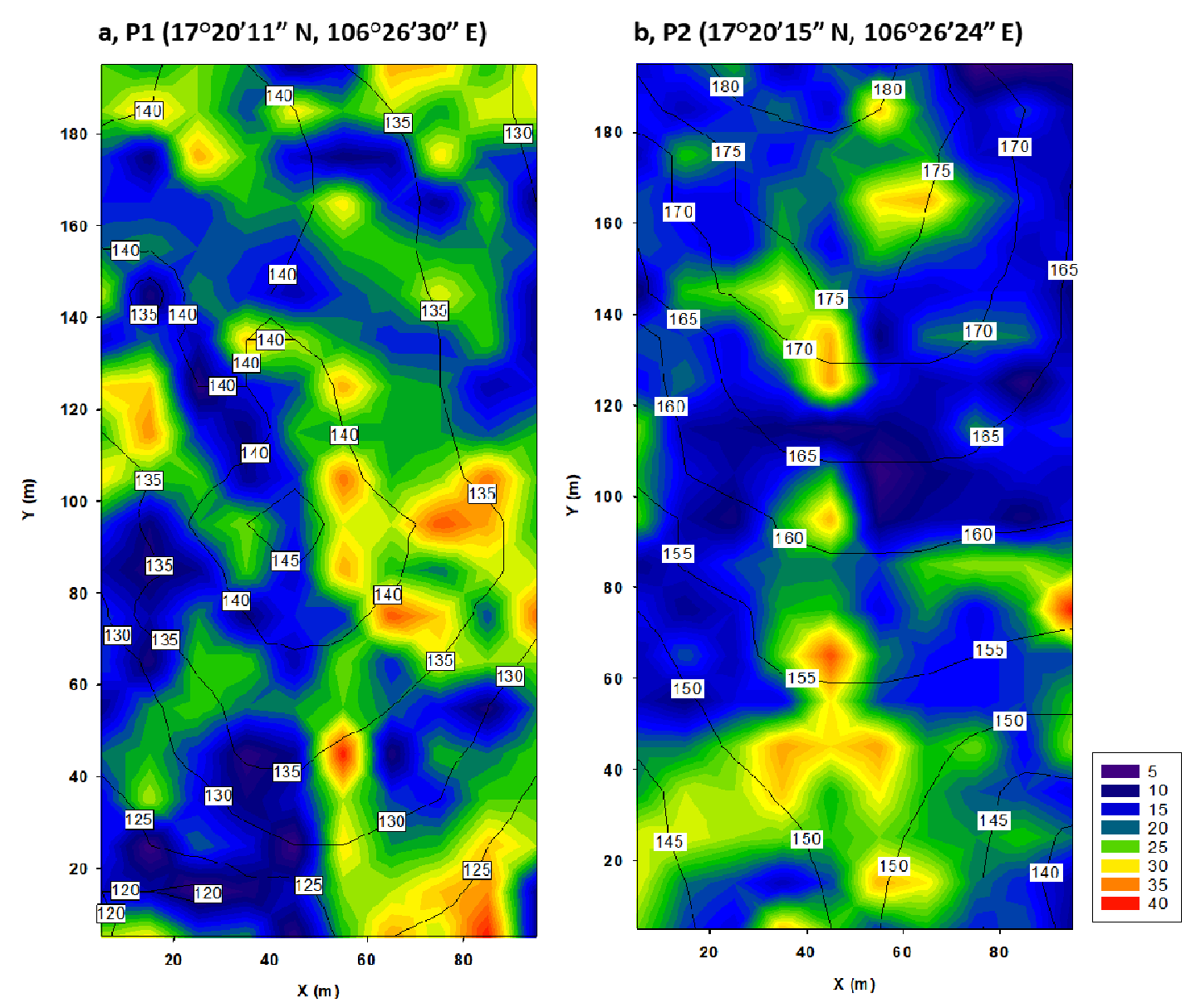

Figure 2. Contour maps of tree density and elevation in the two 2-ha plots P1 (a) and P2 (b). Colors indicate tree density of subplots. Contours show $5 \mathrm{~m}$ intervals of elevation.

Differences between the two plots (sites) in structural traits (species richness, abundance, Simpson index, Shannon index, Evenness, Canopy cover, Basal area, AGB) and in topographical parameters (slope, altitude, and aspect) were tested by one-way analysis of variance (ANOVA) considering plots as factors (categorical variable). If the ANOVA provides us with a significant site effect (F-test, $p<0.05$ ), the differences in structural traits between both plots are examined by the Scheffe post hoc test. Prior to the ANOVA, the Kolmogorov-Smirnov and Levene's tests were performed to assess normality of residuals and homoscedasticity of variance, respectively. If the data did not comply with the requirements of parametric tests (i.e., heteroscedasticity of variance, $p<0.05$ in Levene's test), the differences of the plots were examined by the non-parametric Mann-Whitney $U$ test.

\subsubsection{Topographical Effects on Community Properties}

The difference in biotic characteristics between the plots under heterogeneous topographic environment was examined, including number of species individuals, abundance, basal area, and AGB, and species diversity indices (i.e., Simpson, Shannon, and Evenness) and topographic variables (i.e., elevation, slope, and aspect) by non-metric multidimensional scaling (NMDS), using abundance-based Bray-Curtis dissimilarity matrices (adjustment no-share $=0.1$; number of permutations $=999$ ). The R software ver. 3.5.1 [32] and the package vegan ver. 2.4-5 [33] were used. To get insights into topographical- 
community pattern relations, we fitted topographical factors onto NMDS ordinations using the envfit function in the vegan package, and goodness of fit and $p$-value were permuted 999 times. In addition, species richness, Shannon, Simpson, and Evenness indices were fitted to NMDS ordinations to test whether these individual variables were associated with community patterns.

\subsubsection{Overall Species-Species Associations}

The interspecific interactions of species within two study plots were compared by the classification scheme proposed by Wiegand et al. [14]. The classification scheme may provide valuable information about species coexistence in species-rich communities. We employed this approach to explore the effects of environmental heterogeneity on biotic interactions of the same species within two study plots as the scheme can be used to study first-order effects due to habitat heterogeneity on species associations. Interspecific associations were classified into four schemes based on the bivariate forms of $K$-function, $K_{12}(r)$, and the nearest neighbor distribution function, $D_{12}(r)[4,20]$. The $K$-function, $K_{12}(r)$, is the bivariate Ripley's function [34]. The $D_{12}(r)$ is the cumulative nearest neighbor distribution function that exhibits the probability that an individual of species 2 is located within distance $r$ of an individual of species 1 . We used a null model in which the spatial location of individuals of focal species were remained unchanged while individuals of species 2 were arranged randomly and independently from the spatial locations of individuals of species 1 [35]. The expectations of the summary statistics, i.e., $K_{12}(r)$ and $D_{12}(r)$, under the null model result in:

$$
K_{12}(\mathrm{r})=\pi r^{2} \text { and } D_{12}(r)=\left(1-\exp \left(-\lambda^{2} \pi r^{2}\right)\right)
$$

Therefore, the classification scheme with the two axes $\hat{P}(r)$ and $\hat{M}(r)$ were defined as:

$$
\hat{P}(r)=\hat{D}_{12}(r)-\left(1-\exp \left(-\lambda_{2} \pi r^{2}\right)\right) ; \hat{M}(r)=\ln \left(\hat{K}_{12}(r)\right)-\ln \left(\pi r^{2}\right)
$$

The two-dimensional scheme allows identifying four fundamental types of bivariate associations, as explained in Table 1.

Table 1. The types of association identified by the classification scheme.

\begin{tabular}{lc}
\hline \multicolumn{1}{c}{ Type of Association } & \multicolumn{1}{c}{ Function } \\
\hline $\begin{array}{l}\text { Segregation (i.e., less individuals of species 2 } \\
\text { on average around species 1 than expected } \\
\text { by chance) }\end{array}$ & $\hat{M}(r)<0$ and $\hat{P}(r)<0$ \\
$\begin{array}{l}\text { Partial overlap (i.e., frequent individuals of } \\
\text { species 2 around some individuals of species 1, } \\
\text { despite others) }\end{array}$ & $\hat{M}(r)>0$ and $\hat{P}(r)<0$ \\
$\begin{array}{l}\text { Mixing (i.e., frequent individuals of species 2 } \\
\text { around individuals of species 1) } \\
\text { Type IV (i.e., overlapping of individuals of } \\
\text { species 2 on dense cluster of individuals of } \\
\text { species 1 and 2) }\end{array}$ & $\hat{M}(r)>0$ and $\hat{P}(r)>0$ \\
\hline
\end{tabular}

Species pairs showing non-significant effects for a spatial distance $r$ in the summary statistics are classified as 'no association' and will appear close to the center of the scheme.

To stabilize the variance, a transformation of $K_{12}(r), L_{12}(r)=\left(K_{12}(r) / \pi\right)^{0.5}$ was used instead of $K_{12}(r)$.

The two summary statistics were generated from 199 simulations by using Programita software (http:/ / programita.org/ accessed on 1 December 2020) with a distance bin of $1 \mathrm{~m}$. The goodness-of-fit test was conducted to evaluate a significant departure of the empirical summary statistics from the null model, at an error rate of $5 \%$. Because of using 
two summary statistics, $K \mathrm{ij}(r)$ and $D \mathrm{ij}(r)$, at the same time, the rank larger than 195 was considered to be significant.

\section{Results}

In total, 3732 and 3698 tree individuals of 61 and 52 species were recorded in P1 and $\mathrm{P} 2$, respectively. Both plots shared 47 identical species, and the most abundant species were Ormosia balansae (Fabaceae), Garuga pierrei and Bursera tonkinensis (Burseraceae), Tarrietia javanica (Malvaceae), Paviesia annamensis (Sapindaceae), and Litsea glutinosa (Lauraceae) (Appendix A).

\subsection{Community Properties}

The null hypothesis of homoscedasticity of variances was rejected for Species richness, Abundance, Total basal area, Canopy cover, Elevation, Aspect, and AGB $(p<0.05$, Levene test, Table 2), and therefore the effect of site/plot on these parameters was tested by applying of non-parametric $U$ test. The structural traits Abundance and Canopy cover were found to be higher in P1 compared to P2, whereas Total basal area, AGB, and Elevation showed the opposite (Table 2). Species richness and Aspect did not vary significantly between plots. In the case of the other tested parameters (Simpson, Shannon, Evenness, and Slope), the null hypothesis of homoscedasticity of variances was accepted and consequently, we were allowed to apply the Scheffe post hoc test. For all three diversity indices (Simpson, Shannon, and Evenness), but also for slope, the mean values of $\mathrm{P} 2$ were significantly higher than those of P1 $(p<0.05$, Scheffe test, Table 2).

Table 2. Basic description of the two study plots.

\begin{tabular}{|c|c|c|c|c|c|}
\hline \multirow{2}{*}{$\begin{array}{c}\text { Characteristics } \\
\text { (Mean } \pm \text { SD) }\end{array}$} & \multirow{2}{*}{ P1 } & \multirow{2}{*}{$\mathbf{P 2}$} & \multicolumn{3}{|c|}{$p$-Value for the Test } \\
\hline & & & Levene's & Post Hoc Scheffe & Mann-Whitney \\
\hline Elevation (m) & $134.30 \pm 6.32 \mathrm{a}$ & $160.67 \pm 11.09 \mathrm{~b}$ & $<0.001$ & & $<0.001$ \\
\hline Slope $\left(^{\circ}\right)$ & $20.22 \pm 6.61 \mathrm{a}$ & $26.6 \pm 7.54 \mathrm{~b}$ & 0.203 & $<0.001$ & \\
\hline Aspect $\left(^{\circ}\right)$ & $87.51 \pm 55.46 \mathrm{a}$ & $91.08 \pm 47.96 \mathrm{a}$ & $<0.001$ & & 0.413 \\
\hline Species richness & $11.39 \pm 2.38 \mathrm{a}$ & $11.48 \pm 2.68 \mathrm{a}$ & 0.013 & & 0.533 \\
\hline Abundance & $19.67 \pm 5.19 \mathrm{a}$ & $18.69 \pm 6.35 b$ & 0.018 & & 0.025 \\
\hline Canopy cover (\%) & $83.38 \pm 4.52 \mathrm{a}$ & $81.01 \pm 7.37 \mathrm{~b}$ & $<0.001$ & & $<0.001$ \\
\hline Shannon index & $2.22 \pm 0.36 \mathrm{a}$ & $2.29 \pm 0.29 b$ & 0.605 & 0.035 & \\
\hline Simpson index & $0.87 \pm 0.04 \mathrm{a}$ & $0.88 \pm 0.03 b$ & 0.258 & 0.024 & \\
\hline Evenness index & $0.85 \pm 0.07 \mathrm{a}$ & $0.88 \pm 0.06 \mathrm{~b}$ & 0.391 & 0.002 & \\
\hline Total basal area $\left(\mathrm{m}^{2}\right)$ & $0.24 \pm 0.15 \mathrm{a}$ & $0.32 \pm 0.18 \mathrm{~b}$ & $<0.001$ & & $<0.001$ \\
\hline AGB $(\mathrm{Mg})$ & $1559.27 \pm 1406.18 \mathrm{a}$ & $2152.42 \pm 1545.60 \mathrm{~b}$ & 0.005 & & $<0.001$ \\
\hline
\end{tabular}

Values for a parameter marked by different letters differ significantly $(p<0.05)$. SD- standard deviation

\subsection{Effects of Topography on Community Properties}

The NMDS ordination (Figure 3) showed that community compositions in the two study plots were significantly influenced by topographical variables (details in Appendix B). In P1 (Figure 3a), the NMDS plot indicated three topographical variables, including slope $\left(R^{2}=0.05, p=0.006\right)$, elevation $\left(R^{2}=0.06, p=0.004\right)$, and aspect $\left(R^{2}=0.03, p=0.04\right)$, significantly affecting community composition. The two topographical variables, elevation and slope, appeared to be positively associated with Abundance $\left(R^{2}=0.20, p=0.001\right)$ and Shannon index $\left(R^{2}=0.12, p=0.001\right)$, while Aspect was positively associated with Evenness $\left(R^{2}=0.27, p=0.001\right)$. Other properties including AGB, Basal area, and Canopy cover were not significantly associated with any topographical variable $(p>0.05)$. 
a, P1

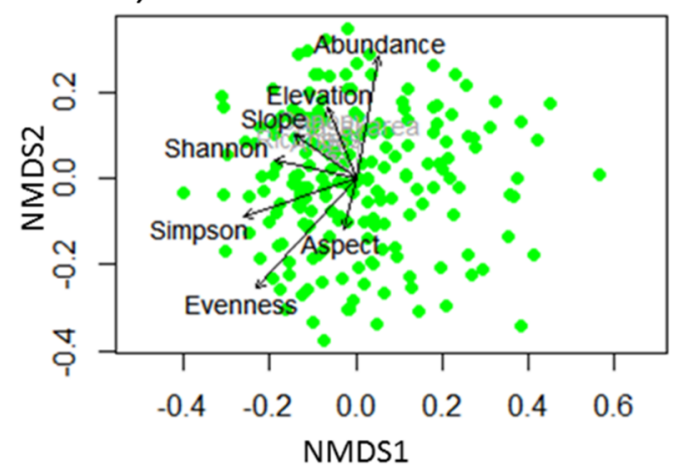

b, P2

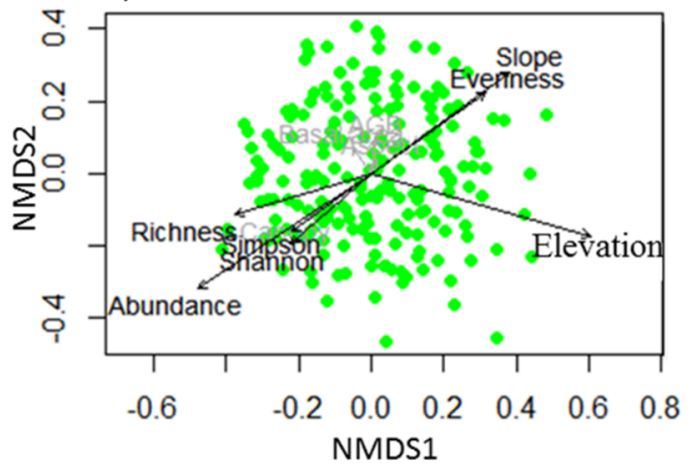

Figure 3. NMDS ordination showed the effects of topographical variables on the compositional structure of the forest plots: P1 (a) and P2 (b) with stress value $=0.09$. The significant variables $(p<0.05)$ were displayed in black arrows and non-significant variables $(p>0.05)$ in grey.

Interestingly, in P2 (Figure 3b), Slope $\left(\mathrm{R}^{2}=0.11, p=0.001\right)$ showed a strong correlation with Evenness $\left(R^{2}=0.07, p=0.001\right)$. Although Aspect $\left(R^{2}=0.0007, p=0.93\right)$ significantly affected Community composition, this topographical variable did not show any relationship with the examined community properties. Similarly to P1, AGB, Basal area, and Canopy cover did not have any links with topographical variables.

\subsection{Overall Species-Species Associations}

In total, 420 species pairs of 20 most abundant species with more than 50 individuals in P1 and P2 (Appendix A) were analyzed. The associations of the same heterospecific pairs were influenced by environmental heterogeneity. For example, Tarrietia javanica and Mallotus paniculatus showed spatial segregation in P1 (Figure 4c), which means that individuals of $M$. paniculatus occurred consistently less around individuals of T. javanica at spatial scales of $0-10 \mathrm{~m}$, however, these two species showed partial overlap in P2 (Figure 4f). Individuals of M. paniculatus occurred more often within neighborhoods (up to $10 \mathrm{~m}$ distance) of $T$. javanica, while a notable proportion of $T$. javanica on average has less individuals of M. paniculatus as their neighbors. Additionally, T. javanica and Bursera tonkinensis were spatially mixed in P1 (Figure 4e). Individuals of B. tonkinensis were observed around individuals of T. javanica more than expected, at a 0-10 m distance, while they were independently distributed in P2 (Figure 4h), which means that the individuals of the species were not spatially associated.

The overall interspecific interactions of tree species up to scales of $50 \mathrm{~m}$ showed that independence patterns were the most dominant association type of tree species and were similar in both study plots, $>50 \%$ in P1 and $49 \%$ in P2, of species pairs (Figure 5). Significant patterns increased with increasing distances up to $10 \mathrm{~m}$, then declined and disappeared at distances larger than $30 \mathrm{~m}$ in P1 and $40 \mathrm{~m}$ in P2 (Figure 5). Partial overlapping and segregation were the dominant association types in P1, while they were shuffled in P2. In addition, we observed less spatial mixing of tree species in P1 compared to P2, although clustering of species (type IV) was not significantly different in both plots. 

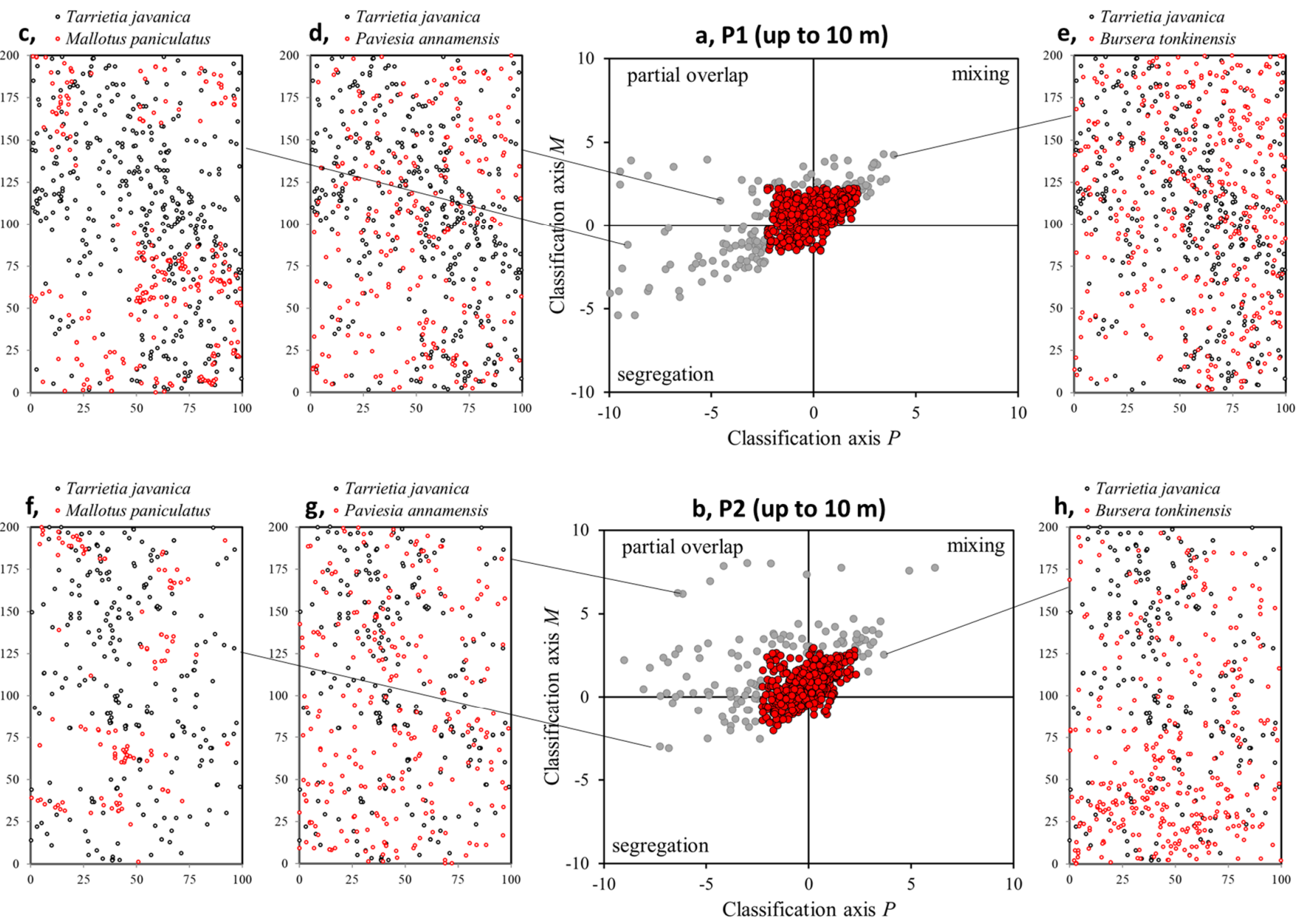

h, Tarrietia javanica
. Bursera tonkinensis
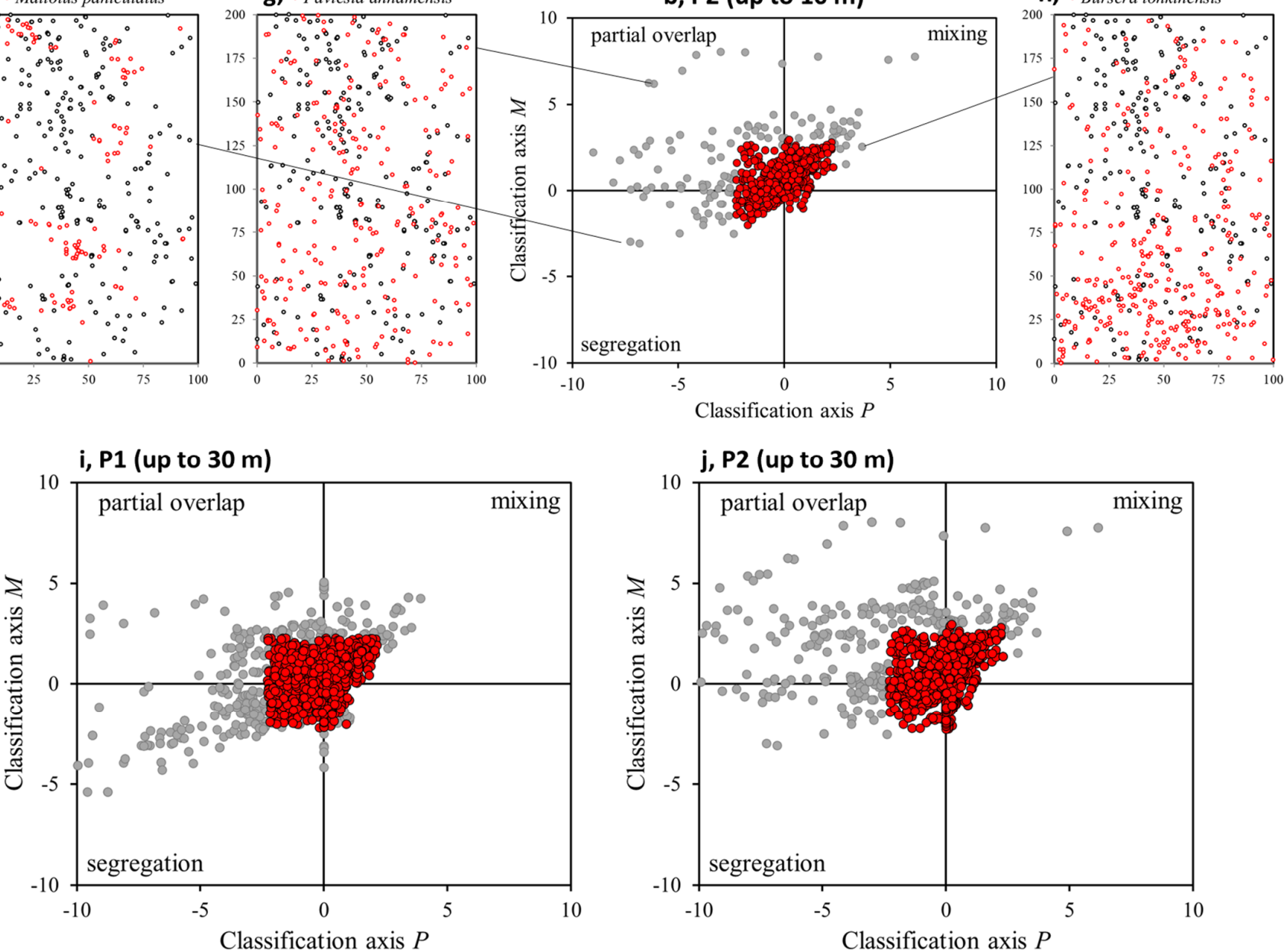

Figure 4. Classification of species-species associations at the two study plots. Overall species associations of 420 species pairs were allocated based on $P(r)$ and $M(r)$ at small spatial scale $(0-10 \mathrm{~m})(\mathbf{a}, \mathbf{b})$ and large spatial scale $(0-30 \mathrm{~m})(\mathbf{i}, \mathbf{j})$ in P1 and P2. The grey circles indicated significant species-species association types, while red circles showed no significant departure from the null model of independence. Examples: (c) Segregation: T. javanica vs. M. paniculatus in P1. (d) Partial overlap: T. javanica vs. P. annamensis in P1. (e) Mixing: T. javanica vs. B. tonkinensis in P1. (f) Segregation: T. javanica vs. M. paniculatus in P1 changed to partial overlapping in P2. (g) Partial overlapping: T. javanica vs. P. annamensis in P1 turned to independence in P2. (h) Independence: T. javanica vs. B. tonkinensis in P2 that were mixed in P1. In panels (c-h), black dots are the focal species (=i, i.e., T. javanica) and red dots are secondary species $(=\mathbf{j})$. 


\section{a. P1}

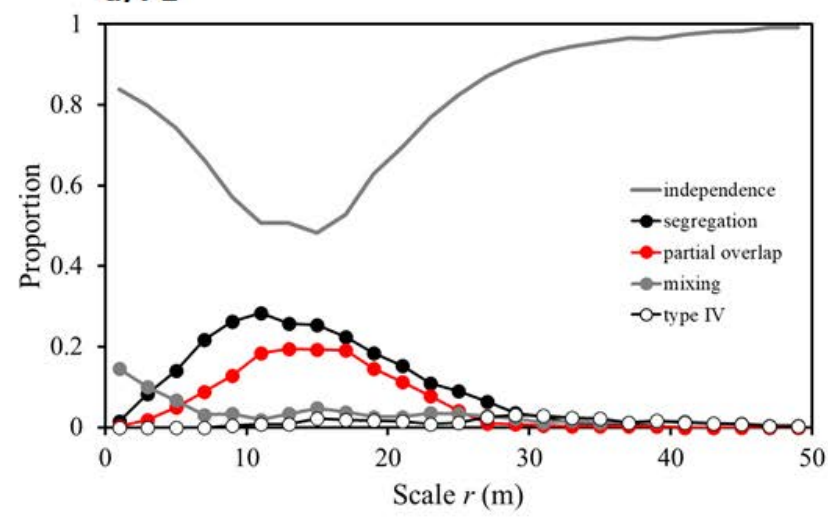

b. $\mathbf{P 2}$

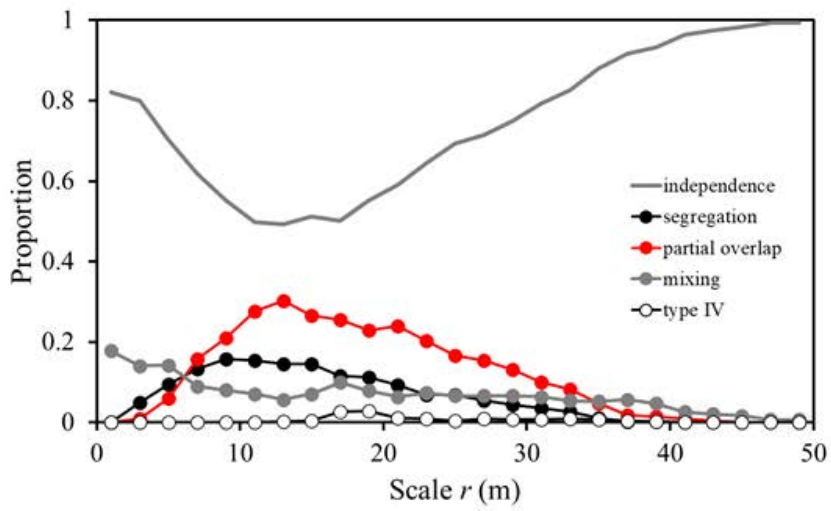

Figure 5. The overall interspecific associations of 20 species and their spatial scale-dependences in P1 (a) and P2 (b).

The results showed that species segregations were higher in proportion and peaked at $10 \mathrm{~m}$, with 119 species pairs (28\%) in P1 compared to 65 species pairs (15\%) in P2. Partial overlap of species association increased, and the highest proportion was observed at neighborhoods of $13 \mathrm{~m}$ with 82 pairs (19\%), then decreased. Partial overlap in P2 (127 pairs, $30 \%$ ) was at higher proportion and lasted to larger spatial scales, up to $40 \mathrm{~m}$ compared to $30 \mathrm{~m}$ in P1. Species mixing was found at a lower proportion of 0.14 in P1 (61 pairs, 14\%) and decreased to low proportions at spatial scales of $30 \mathrm{~m}$, while it peaked at a proportion of 0.18 (75 pairs, 17\%) and remained stable up to large scales of $50 \mathrm{~m}$ in P2. No associations (type IV) were dominant at very low proportions up to large scales of $50 \mathrm{~m}$ in both study plots (Figure 5). In general, environmental heterogeneity in P2 could increase extreme cases of partial overlap, decrease segregation, and retain the spatial patterns at larger scales compared to that in P1.

\section{Discussion}

Our results showed significant effects of topographic heterogeneity on community composition and species associations. Species diversity and community structure strongly correlated with the topographic variables, i.e., Elevation, Slope, and Aspect. Interspecific associations such as spatial segregation, partial overlap, and mixing were dominant interaction types at small spatial scales up to $30 \mathrm{~m}$, while the effects of habitat heterogeneity occurred at larger scales.

\subsection{Topographical Effects on Community Properties}

The association of plant species and their habitats have long been investigated by correlating indices of local properties and habitat variables $[6,17,36,37]$. Species-habitat associations at large scales caused by biophysical gradients have been observed in tropical forests such as altitudinal zones [38], meso-scales of 1-50 ha [6,36], and landscape scales [39], while investigations at small scales have recently been receiving attention [40,41]. Our analyses using $10 \times 10 \mathrm{~m}$ quadrats for measures of topographic variables and individual tree locations show that microhabitat differentiation and microhabitat-species association also exist at this fine scale.

A better understanding of the relationship between spatial changes in environmental conditions and the underlying physiological processes may be explored by comparison of demographic rates according to habitat characteristics [42]. However, the degree to which variation in species spatial distribution is explained by topographic variation is negligible. For example, Guo et al. [41] found $16.7 \%$ of the total variance in species abundance combining with seven topographical variables including elevation, slope, convexity, slope, rock-bareness rate, topographical wetness index, and altitude above channel at a spatial 
scale of $10 \times 10 \mathrm{~m}$ in a 15 ha study area in tropical karst seasonal rainforests, China. The authors emphasized the overall strong evidence of topography on spatial species patterns and a negligible effect of spatially independent habitat. In another 20 ha study area within tropical rainforests in Xishuangbanna, China, Lan et al. [43] also found strong evidence for the effects of topographic variables on species distribution; however, topographic variables explained a small proportion of the observed variation. Moreover, Liu et al. [44] explored significant changes of species composition and mixture along the topographical gradient within the similar forests.

\subsection{Overall Species-Species Associations}

The most significant interactions between tree species occurred in their neighborhood spatial scales, as spacing between heterospecifics was closely related to coexistence mechanisms $[22,23,45]$. In our study, approximately $50 \%$ of species pairs showed significant interactions: the percentage of species pairs having significant interactions increased with increasing spatial scales up to 10-15 $\mathrm{m}$, then declined and disappeared at larger scales of 30-40 m. Segregation and partial overlap were the dominant association types and decreased with increasing distances up to $30-50 \mathrm{~m}$ in our study plots.

In a 25 ha study area in tropical dipterocarp forests of Sri Lanka, Wiegand et al. [14] found that a significant neighborhood of plant interactions occurred within small spatial scales (i.e., 2-4 m) and disappeared within scales of $15-20 \mathrm{~m}$ from the focal plant individuals. Moreover, among interspecific associations of 46 species, approximately $50.2 \%$ showed segregation, 5.4\% mixing, and 34\% partial overlap. Wang et al. [46] analyzed 15 common species associations in a 25 ha temperate forest of Changbaishan, China, and found $54.8 \%$ of segregation in small scales up to $15 \mathrm{~m}, 20 \%$ of partial overlap, and $6.2 \%$ of mixing. Positive associations were rare in local neighborhoods and only $8 \%$ of species pairs co-occurred at large spatial scales. In addition, Velázquez et al. [47] explored that almost $50 \%$ of the 64 species pairs showed no significant associations and strong positive spatial patterns occurred in spatial scales of 5 and $30 \mathrm{~m}$ and negative patterns in a $5 \mathrm{~m}$ neighborhood within a 50 ha study plot in tropical forests at Barro Colorado Island. These studies lend support for the significant effects of environmental heterogeneity on species interaction and suggest that the tendency of species segregation may be a supplementary effect of processes promoting species coexistence [14], evidences of competitive interaction among species [46,48], or topographic habitat preference-related species associations at small and large scales [47]. Wiegand et al. [4] examined the independence of tree species associations from three large study plots in tropical forests with high biodiversity at Barro Colorado Island (Panama), tropical dipterocarp forests at Sinharaja (Sri Lanka), and temperate forests at Changbaishan (China). The authors found no significant heterospecific association that was increased with species richness; however, segregation and small-scale interaction of heterospecifics were decreased with species richness. They suggested that independence may be the dominant association type in communities with high biodiversity. Our findings are in line with those mentioned above as well as other studies (e.g., Nguyen et al. [26], Zhou et al. [48]) using the approach of classification scheme for association patterns of tree species.

In this study, we found that partial overlapping and segregation dominate the entire species association at small spatial scales. The spatial segregation is hypothesized as a mechanism that reduces the possibility of encounters shaping highly diverse communities and facilitates species coexistence [49], which is maintained by the balanced extent of intra- and inter-specific competitions [22,23]. If aggregated patterns of conspecifics cause segregation of other species from clusters, it can be inferred that the intraspecific competition is more important than the interspecific competition, resulting in enhancement of species coexistence $[4,49]$. Moreover, the species herd protection hypothesizes that interspecific neighborhood can promote co-existence of species by biological mechanisms such as preventing biotic plant pests to be transmitted, therefore increasing positive interactions between species $[7,50]$. Spatial segregation may also be a result of environmental 
heterogeneity in which a negative association of species individuals can be observed if the two species show dissimilarity in habitat preferences [4]. Zhou et al. [48] argued that interspecific spatial patterns generate spatial segregation and partial overlap under habitat heterogeneity, in addition, frequently negative associations might be a result of resource competition. Our results suggest that aggregation of conspecifics may not be strong enough to shape local dominance and provide evidence of the reduction of species richness according to aggregation of conspecifics and segregation of heterospecifics that comply with previous studies in species-rich communities $[4,23,45,51]$.

\section{Conclusions}

Our analyses revealed that environmental heterogeneity remained the important driver in maintaining species associations in species-rich forest communities. Spatial segregation, partial overlap, and mixing were displayed at different frequencies and spatial scales smaller than $30 \mathrm{~m}$ of species associations. Here, topographical variables such as Elevation, Slope, and Aspect were the main drivers of habitat heterogeneity. These findings remain for future research to explore the above- and below-ground factors to aid understanding of the underlying processes which structure species patterns, particularly for purposes of sustainable forest management with appropriate silvicultural interventions. Based on our results, we can identify topographically heterogeneous parts of tropical forest stands and concentrate management activities (e.g., thinning) to these areas to prevent species' natural removal, facilitate natural regeneration of focal species, maintain species composition, and/or increase diversity. Though widely applied in forest ecology studies, the approach of spatial point pattern analysis is often costly and time-consuming because of a prerequisite for the stem-mapped data, especially in large plots. However, the applied approach used in this study may be an important scientific tool for decisionmakers involved in forest management planning in a sustainable way, even in the case of heterogeneous, tropical, species-rich forests.

Author Contributions: N.H.H. and T.H.M. conceived/designed the experiment and collected the data; N.H.H., Y.E., V.B.B., and I.C.P. analyzed the data; N.H.H., Y.E., V.B.B., T.H.M., and I.C.P. wrote the paper; A.M.P. designed the study map and revised the paper. All authors have read and agreed to the published version of the manuscript.

Funding: This research is funded by Vietnam National Foundation for Science and Technology Development (NAFOSTED) under grant number 106.06-2019.307.

Institutional Review Board Statement: Not applicable.

Informed Consent Statement: Not applicable.

Data Availability Statement: Data supporting this study are available on request to the first author.

Acknowledgments: We thank the three anonymous reviewers and the editor for the constructive comments and suggestions that improved the previous draft of our manuscript.

Conflicts of Interest: The authors declare no conflict of interest.

\section{Appendix A}

Table A1. Characteristics of Most Abundant Species in P1 and P2.

\begin{tabular}{ccccccccc}
\hline \multirow{2}{*}{ No } & Tree Species & \multicolumn{9}{c}{ P1 } & \multicolumn{2}{c}{ P2 } \\
\cline { 3 - 7 } & & $\mathbf{N}$ & $\mathbf{D B H} \mathbf{( c m )}$ & IVI (\%) & $\mathbf{N}$ & DBH (cm) & IVI (\%) & Shade Tolerance \\
\hline 1 & Garuga pierrei & 282 & $10.08 \pm 10.89$ & 8.98 & 232 & $11.30 \pm 13.26$ & 7.72 & Tolerant \\
2 & Tarrietia javanica & 383 & $5.62 \pm 6.39$ & 7.28 & 330 & $4.52 \pm 3.58$ & 5.14 & Intolerant \\
3 & Ormosia balansae & 138 & $17.05 \pm 12.97$ & 7.26 & 187 & $14.75 \pm 10.81$ & 6.60 & Intolerant \\
4 & Bursera tonkinensis & 384 & $6.15 \pm 4.16$ & 6.72 & 253 & $6.67 \pm 4.12$ & 4.41 & Medium \\
5 & Paviesia annamensis & 240 & $9.18 \pm 7.64$ & 6.02 & 239 & $6.94 \pm 4.86$ & 4.32 & Intolerant \\
6 & Litsea glutinosa & 229 & $8.06 \pm 6.21$ & 4.96 & 264 & $8.26 \pm 6.70$ & 5.49 & Intolerant \\
\hline
\end{tabular}


Table A1. Cont.

\begin{tabular}{|c|c|c|c|c|c|c|c|c|}
\hline \multirow{2}{*}{ No } & \multirow{2}{*}{ Tree Species } & \multicolumn{3}{|c|}{ P1 } & \multicolumn{3}{|c|}{$\mathbf{P 2}$} & \multirow{2}{*}{ Shade Tolerance } \\
\hline & & $\mathbf{N}$ & $\mathrm{DBH}(\mathrm{cm})$ & IVI (\%) & $\mathbf{N}$ & $\mathrm{DBH}(\mathrm{cm})$ & IVI (\%) & \\
\hline 7 & Castanopsis indica & 168 & $10.21 \pm 8.27$ & 4.65 & - & - & & Intolerant \\
\hline 8 & Polyalthia nemoralis & 303 & $5.02 \pm 1.77$ & 4.58 & 244 & $5.53 \pm 1.88$ & 3.78 & Intolerant \\
\hline 9 & Syzygium wightianum & 179 & $9.36 \pm 7.04$ & 4.40 & 81 & $11.56 \pm 8.17$ & 1.54 & Intolerant \\
\hline 10 & Erythrophfloeum fordii & 63 & $18.52 \pm 15.35$ & 3.96 & - & - & - & Medium \\
\hline 11 & Mallotus kurzii & 265 & $4.01 \pm 0.98$ & 3.76 & 114 & $3.71 \pm 0.73$ & 1.63 & Intolerant \\
\hline 12 & Amoora dasyclada & 148 & $7.99 \pm 6.73$ & 3.28 & 96 & $8.89 \pm 6.93$ & 2.08 & Medium \\
\hline 13 & Cinnamomun bejolghota & 100 & $10.71 \pm 9.25$ & 3.00 & 267 & $13.01 \pm 10.59$ & 8.51 & Intolerant \\
\hline 14 & Gironniera Subaequalis & 92 & $9.71 \pm 6.65$ & 2.27 & 137 & $11.19 \pm 9.28$ & 3.73 & Medium \\
\hline 15 & Endosperrmun sinensis & 54 & $11.77 \pm 13.18$ & 2.14 & 83 & $21.67 \pm 13.33$ & 4.63 & Intolerant \\
\hline 16 & Garcinia oblongifolia & 121 & $6.23 \pm 4.08$ & 2.11 & 67 & $6.22 \pm 3.48$ & 1.11 & Tolerant \\
\hline 17 & Canarium album & - & - & - & 155 & $11.03 \pm 6.04$ & 3.68 & Intolerant \\
\hline 18 & Koilodepas hainanense & 104 & $5.83 \pm 2.61$ & 1.68 & 80 & $8.41 \pm 4.52$ & 1.54 & Tolerant \\
\hline 19 & Cassine glauca & 74 & $8.41 \pm 5.51$ & 1.59 & 89 & $8.69 \pm 7.66$ & 1.97 & Tolerant \\
\hline 20 & Litsea vang & 71 & $6.54 \pm 3.30$ & 1.27 & 76 & $8.72 \pm 4.67$ & 1.5 & Intolerant \\
\hline 21 & Symplocos laurina & 55 & $9.31 \pm 5.61$ & 1.25 & 145 & $11.81 \pm 6.86$ & 3.71 & Intolerant \\
\hline 22 & Engelhardtia roxburghiana & - & - & & 63 & $28.78 \pm 11.91$ & 4.84 & Tolerant \\
\hline
\end{tabular}

N-Number of individuals, IVI-Important Value Index, (relative abundance + relative basal area)/2, expressed as percentage proportion. DBH-Diameter at Breast Height (mean \pm standard deviation).

\section{Appendix B}

Table A2. NMDS Ordination of the Compositional Structures with Topography in P1 and P2.

\begin{tabular}{cccccccccc}
\hline \multirow{2}{*}{ Properties } & \multicolumn{2}{c}{ Plot P1 } & & \multicolumn{3}{c}{ Plot P2 } \\
\cline { 2 - 9 } & NMDS1 & NMDS2 & $\mathbf{r}^{2}$ & Pr (>r) & NMDS1 & NMDS2 & $\mathbf{r}^{2}$ & Pr (>r) \\
\hline Richness & -0.84966 & -0.52733 & 0.0412 & 0.016 & -0.95625 & -0.29256 & 0.0775 & 0.001 \\
\hline Abundance & 0.08552 & -0.99634 & 0.2051 & 0.001 & -0.82451 & -0.56584 & 0.1677 & 0.001 \\
\hline Canopy cover & -0.57273 & -0.81974 & 0.0292 & 0.051 & -0.8942 & -0.44766 & 0.017 & 0.171 \\
\hline Basal area & 0.01327 & -0.99991 & 0.0204 & 0.159 & -0.33053 & 0.9438 & 0.0047 & 0.678 \\
\hline Simpson & -0.95727 & 0.28919 & 0.1998 & 0.001 & -0.82216 & -0.56926 & 0.0379 & 0.025 \\
\hline Shannon & -0.97059 & -0.24074 & 0.1194 & 0.001 & -0.76235 & -0.64716 & 0.0444 & 0.009 \\
\hline Evenness & -0.65468 & 0.7559 & 0.2773 & 0.001 & 0.80735 & 0.59007 & 0.0731 & 0.001 \\
\hline AGB & -0.76702 & -0.64163 & 0.0121 & 0.315 & 0.21548 & 0.97651 & 0.0085 & 0.457 \\
\hline Elevation & -0.25379 & -0.96726 & 0.0634 & 0.004 & 0.96418 & -0.26524 & 0.2172 & 0.001 \\
\hline Slope & -0.81517 & -0.57922 & 0.0572 & 0.006 & 0.80928 & 0.58743 & 0.1188 & 0.001 \\
\hline Aspect & -0.24281 & 0.97007 & 0.033 & 0.04 & -0.10431 & 0.99454 & 0.0007 & 0.927 \\
\hline
\end{tabular}

NMDS1 and NMDS2: Non-metric multidimensional scaling axes, r: proportion, Pr: significance.

\section{References}

1. Chesson, P. Mechanisms of maintenance of species diversity. Annu. Rev. Ecol. Syst. 2000, 31, 343-366. [CrossRef]

2. Wright, J.S. Plant diversity in tropical forests: A review of mechanisms of species coexistence. Oecologia 2002, 130, 1-14. [CrossRef]

3. May, F.; Huth, A.; Wiegand, T. Moving beyond abundance distributions: Neutral theory and spatial patterns in a tropical forest. Proc. R. Soc. B Biol. Sci. 2015, 282, 20141657. [CrossRef]

4. Wiegand, T.; Huth, A.; Getzin, S.; Wang, X.; Hao, Z.; Gunatilleke, C.S.; Gunatilleke, I.N. Testing the independent species' arrangement assertion made by theories of stochastic geometry of biodiversity. Proc. R. Soc. B. 2012, 279, 3312-3320. [CrossRef]

5. Volkov, I.; Banavar, J.R.; Hubbell, S.P.; Maritan, A. Inferring species interactions in tropical forests. Proc. Natl. Acad. Sci. USA 2009, 106, 13854-13859. [CrossRef] [PubMed]

6. Harms, K.E.; Condit, R.; Hubbell, S.P.; Foster, R.B. Habitat associations of trees and shrubs in a 50-ha neotropical forest plot. J. Ecol. 2001, 89, 947-959. [CrossRef] 
7. Nguyen, H.H.; Uria-Diez, J.; Wiegand, K. Spatial distribution and association patterns in a tropical evergreen broad-leaved forest of north-central Vietnam. J. Veg. Sci. 2016, 27, 318-327. [CrossRef]

8. May, F.; Giladi, I.; Ziv, Y.; Jeltsch, F. Dispersal and diversity-unifying scale-dependent relationships within the neutral theory. Oikos 2012, 121, 942-951. [CrossRef]

9. Adler, P.B.; Fajardo, A.; Kleinhesselink, A.R.; Kraft, N.J. Trait-based tests of coexistence mechanisms. Ecol. Lett. 2013, 16, 1294-1306. [CrossRef]

10. Shipley, B.; Paine, C.T.; Baraloto, C. Quantifying the importance of local niche-based and stochastic processes to tropical tree community assembly. Ecology 2012, 93, 760-769. [CrossRef]

11. Kraft, N.J.; Ackerly, D.D. Functional trait and phylogenetic tests of community assembly across spatial scales in an Amazonian forest. Ecol. Monogr. 2010, 80, 401-422. [CrossRef]

12. Hubbell, S.P.; Ahumada, J.A.; Condit, R.; Foster, R.B. Local neighborhood effects on long-term survival of individual trees in a neotropical forest. Ecol. Res. 2001, 16, 859-875. [CrossRef]

13. Uriarte, M.; Condit, R.; Canham, C.D.; Hubbell, S.P. A spatially explicit model of sapling growth in a tropical forest: Does the identity of neighbours matter? J. Ecol. 2004, 92, 348-360. [CrossRef]

14. Wiegand, T.; Gunatilleke, S.; Gunatilleke, N. Species associations in a heterogeneous Sri lankan dipterocarp forest. Am. Nat. 2007, 170, E77-E95. [CrossRef]

15. Lan, G.; Getzin, S.; Wiegand, T.; Hu, Y.; Xie, G.; Zhu, H.; Cao, M. Spatial Distribution and Interspecific Associations of Tree Species in a Tropical Seasonal Rain Forest of China. PLoS ONE 2012, 7, e46074. [CrossRef]

16. Aiba, S.; Kitayama, K.; Takyu, M. Habitat associations with topography and canopy structure of tree species in a tropical montane forest on Mount Kinabalu, Borneo. Plant Ecol. 2004, 174, 147-161. [CrossRef]

17. Punchi-Manage, R.; Wiegand, T.; Wiegand, K.; Getzin, S.; Gunatilleke, C.S.; Gunatilleke, I.N. Effect of spatial processes and topography on structuring species assemblages in a Sri Lankan dipterocarp forest. Ecology 2014, 95, 376-386. [CrossRef]

18. Lai, J.; Mi, X.; Ren, H.; Ma, K. Species-habitat associations change in a subtropical forest of China. J. Veg. Sci. 2009, 20, 415-423. [CrossRef]

19. Illian, J.; Penttinen, A.; Stoyan, H.; Stoyan, D. Statistical Analysis and Modelling of Spatial Point Patterns; John Wiley \& Sons: Hoboken, NJ, USA, 2008; Volume 70.

20. Wiegand, T.; Moloney, K.A. Handbook of Spatial Point-Pattern Analysis in Ecology; CRC Press: Boca Raton, FL, USA, 2014.

21. Law, R.; Illian, J.; Burslem, D.F.; Gratzer, G.; Gunatilleke, C.V.S.; Gunatilleke, I.A.U.N. Ecological information from spatial patterns of plants: Insights from point process theory. J. Ecol. 2009, 97, 616-628. [CrossRef]

22. Pacala, S.W.; Levin, S.A. Biologically generated spatial pattern and the coexistence of competing species. In Spatial Ecology: The Role of Space in Population Dynamics and Interspecific Interactions; Princeton University Press: Princeton, NJ, USA, 1997; pp. 204-232.

23. Stoll, P.; Prati, D. Intraspecific aggregation alters competitive interactions in experimental plant communities. Ecology 2001, 82, 319-327. [CrossRef]

24. McGill, B.J. Towards a unification of unified theories of biodiversity. Ecol. Lett. 2010, 13, 627-642. [CrossRef] [PubMed]

25. Getzin, S.; Wiegand, T.; Wiegand, K.; He, F. Heterogeneity influences spatial patterns and demographics in forest stands. J. Ecol. 2008, 96, 807-820. [CrossRef]

26. Nguyen, H.H.; Erfanifard, Y.; Pham, V.D.; Le, X.T.; Petritan, I.C. Spatial Association and Diversity of Dominant Tree Species in Tropical Rainforest, Vietnam. Forests 2018, 9, 615. [CrossRef]

27. Tichý, L. Field test of canopy cover estimation by hemispherical photographs taken with a smartphone. J. Veg. Sci. 2016, 27, 427-435. [CrossRef]

28. Magurran, A.E. Ecological Diversity and Its Measurement; Princeton University Press: Princeton, NJ, USA, 1988.

29. Simpson, E.H. Measurement of diversity. Nature 1949, 163, 688. [CrossRef]

30. Heip, C.H.; Herman, P.M.; Soetaert, K. Indices of diversity and evenness. Oceanis 1998, 24, 61-88.

31. Chave, J.; Réjou-Méchain, M.; Búrquez, A.; Chidumayo, E.; Colgan, M.S.; Delitti, W.B.; Duque, A.; Eid, T.; Fearnside, P.M.; Goodman, R.C.; et al. Improved allometric models to estimate the aboveground biomass of tropical trees. Glob. Chang. Biol. 2014, 20, 3177-3190. [CrossRef] [PubMed]

32. Team, R.C. R: A Language and Environment for Statistical Computing; Ver. 3.5. 1; R Foundation for Statistical Computing: Vienna, Austria, 2018.

33. Oksanen, J. Vegan: An Introduction to Ordination. Available online: http://cran.r-project.org/web/packages/vegan/vignettes/ introvegan.pdf (accessed on 1 December 2020).

34. Ripley, B.D. Modelling spatial patterns. J. R. Stat. Soc. Ser. B (Methodol.) 1977, 39, 172-212. [CrossRef]

35. Wiegand, T.; Moloney, K. Rings, circles, and null-models for point pattern analysis in ecology. Oikos 2004, 104, 209-229. [CrossRef]

36. Comita, L.S.; Condit, R.; Hubbell, S.P. Developmental changes in habitat associations of tropical trees. J. Ecol. 2007, 95, 482-492. [CrossRef]

37. Wang, Z.; Ye, W.; Cao, H.; Huang, Z.; Lian, J.; Li, L.; Wei, S.; Sun, I.F. Species-topography association in a species-rich subtropical forest of China. Basic Appl. Ecol. 2009, 10, 648-655. [CrossRef]

38. Gentry, A.H. Changes in plant community diversity and floristic composition on environmental and geographical gradients. Ann. Mo. Bot. Gard. 1988, 1-34. [CrossRef] 
39. Paoli, G.D.; Curran, L.M.; Zak, D.R. Soil nutrients and beta diversity in the Bornean Dipterocarpaceae: Evidence for niche partitioning by tropical rain forest trees. J. Ecol. 2006, 94, 157-170. [CrossRef]

40. Prada, C.M.; Stevenson, P.R. Plant composition associated with environmental gradients in tropical montane forests (Cueva de Los Guacharos National Park, Huila, Colombia). Biotropica 2016, 48, 568-576. [CrossRef]

41. Guo, Y.; Wang, B.; Li, D.; Mallik, A.U.; Xiang, W.; Ding, T.; Wen, S.; Lu, S.; Huang, F.; He, Y.; et al. Effects of topography and spatial processes on structuring tree species composition in a diverse heterogeneous tropical karst seasonal rainforest. Flora 2017, 231, 21-28. [CrossRef]

42. Lasky, J.R.; Sun, I.F.; Su, S.H.; Chen, Z.S.; Keitt, T.H. Trait-mediated effects of environmental filtering on tree community dynamics. J. Ecol. 2013, 101, 722-733. [CrossRef]

43. Lan, G.; Hu, Y.; Cao, M.; Zhu, H. Topography related spatial distribution of dominant tree species in a tropical seasonal rain forest in China. For. Ecol. Manag. 2011, 262, 1507-1513. [CrossRef]

44. Liu, J.; Yunhong, T.; Slik, J.F. Topography related habitat associations of tree species traits, composition and diversity in a Chinese tropical forest. For. Ecol. Manag. 2014, 330, 75-81. [CrossRef]

45. Raventós, J.; Wiegand, T.; Luis, M.D. Evidence for the spatial segregation hypothesis: A test with nine-year survivorship data in a Mediterranean shrubland. Ecology 2010, 91, 2110-2120. [CrossRef]

46. Wang, X.; Wiegand, T.; Hao, Z.; Li, B.; Ye, J.; Lin, F. Species associations in an old-growth temperate forest in north-eastern China. J. Ecol. 2010, 98, 674-686. [CrossRef]

47. Velázquez, E.; Paine, C.T.; May, F.; Wiegand, T. Linking trait similarity to interspecific spatial associations in a moist tropical forest. J. Veg. Sci. 2015, 26, 1068-1079. [CrossRef]

48. Zhou, Q.; Shi, H.; Shu, X.; Xie, F.; Zhang, K.; Zhang, Q.; Dang, H. Spatial distribution and interspecific associations in a deciduous broad-leaved forest in north-central China. J. Veg. Sci. 2019, 30, 1153-1163. [CrossRef]

49. Chesson, P. General theory of competitive coexistence in spatially-varying environments. Theor. Popul. Biol. 2000, 58, 211-237. [CrossRef] [PubMed]

50. Peters, H.A. Neighbour-regulated mortality: The influence of positive and negative density dependence on tree populations in species-rich tropical forests. Ecol. Lett. 2003, 6, 757-765. [CrossRef]

51. Pacala, S.W. Dynamics of plant communities. Plant Ecol. 1997, 532-555. 